\title{
CHARACTERIZATION OF THE ANTIFUNGAL ACTIVITY AGAINST BOTRYTIS CINEREA OF SCLAREOL AND 13-EPI-SCLAREOL, TWO LABDANE-TYPE DITERPENOIDS
}

\author{
LEONORA MENDOZA*, CAROLINA SEPÚLVEDA, RICARDO MELO, MILENA COTORAS* \\ Laboratorio de Micología, Facultad de Química y Biología, Universidad de Santiago de Chile. Alameda 3363, Santiago, Chile
}

\begin{abstract}
The antifungal activity of Sclareol and 13-epi-Sclareol, two labdane-type diterpenoids, on mycelial growth of the phytopathogenic fungus Botrytis cinerea was evaluated. Diterpenoid fungitoxicity was assessed using the radial growth test method. Both diterpenoids inhibited the mycelial growth of $B$. cinerea in solid medium; however the inhibitory activity of Sclareol was slightly higher than 13-epi-Sclareol with $\mathrm{IC}_{50}$ value of $237.6 \mu \mathrm{g} / \mathrm{mL}$ and $268.8 \mu \mathrm{g} / \mathrm{mL}$, respectively. On the other hand, both labdane-type diterpenoids did not alter the plasmatic membrane integrity; however the oxygen consumption of $B$. cinerea germinating conidia was affected. The evidence suggests that action mechanism of these molecules would be related to the uncoupling of mitochondrial oxidative phosphorylation. Finally, biotransformation of Sclareol by B. cinerea was analysed and the main biotransformed metabolite was identified as $3 \beta$-hydroxysclareol.
\end{abstract}

Keywords: Sclareol, 13-epi-Sclareol, antifungal activity, Botrytis cinerea

\section{INTRODUCTION}

Botrytis cinerea, the agent of gray mold, is a facultative phytopathogenic fungus that affects fruits, leaves, stems and flowers of more than 250 plant species $^{1}$. Chilean climatic conditions such as high relative humidity, wind speed and low temperatures promote a high incidence of this disease, causing serious pre- and postharvest losses in the grape production in Chile 2 .

Currently, the $B$. cinerea control is realized with hydroxyanilides, anilinopyrimidines, dicarboximides, carboxamides, strobilurins, phenylpyrroles and some inhibitors of ergosterol synthesis ${ }^{3}$. These families of fungicides differ in their mechanism of action on the fungus. The prolonged use of these synthetic compounds in the field has caused the development of resistance to these botryticides ${ }^{4-6}$. Therefore, it is imperative to find new and effective molecules with antifungal activity. Secondary metabolites produced by plants are an alternative to control phytopathogenic fungi; some of these constitutive or inducible compounds have shown antimicrobial activity. Among them, diterpenoids are an interesting group of secondary metabolites due to their biological activities. These compounds are widely distributed in nature and it has been described that some have antibacterial ${ }^{7}$, antiviral $^{8}$ and antifungal activities?.

Cotoras et al. (2001) reported the effect of the diterpenoid $3 \beta-$ hydroxykaurenoic acid on the mycelial growth and conidia germination of B. cinerea $^{10}$. Later, the same group reported that the mechanism of action of $3 \beta$-hydroxykaurenoic acid was based on the permeabilization of plasmatic membrane ${ }^{11}$. On the other hand, Mendoza et al. (2009) $)^{12}$ investigated the inhibitory effect of the natural diterpenoids salvic acid, acetylsalvic acid, and three hemisynthetic diterpenoids against $B$. cinerea. All diterpenoids, with the exception of isopentenoylsalvic acid, inhibited the mycelial growth of $B$. cinerea in solid media. Studies on a possible action mechanism of natural diterpenoids, salvic acid and acetylsalvic acid, showed that these diterpenoids exerted their effect by a different mechanism. Salvic acid did not alter cytoplasmic membrane or cause respiratory chain inhibition. Instead, acetylsalvic acid affected the integrity of the cytoplasmic membrane ${ }^{12}$. These results suggest that compounds, as diterpenoids might be good candidates for the design of antifungal compounds.

On the other hand, $B$. cinerea has the ability to biotransform secondary metabolites, producing chemical changes in these compounds ${ }^{13}$. It has been reported that this fungus biotransforms different types of compounds as: steroids, sesquiterpenoids, flavones, diterpenoids, etc. ${ }^{13}$. The main biotransformation reactions involve oxidations and hydroxylations, when $B$. cinerea metabolizes phytoalexins or antifungal compounds as a detoxification mechanism, although reduction reactions have been also described ${ }^{13}$.

Labdane-type diterpenes are examples of natural products with important biological activities. Some of these compounds possess antifungal, antibacterial, antimutagenic, cytotoxic, anti-inflammatory or analgesic activities ${ }^{14}$. On the other hand, the fungal biotransformation of Sclareol has also been studied.

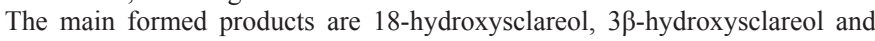
$6 \alpha$-hydroxysclareol ${ }^{14 .}$ It has been reported that $B$. cinerea biotransforms Sclareol to epoxysclareol, and this later to a halogenated product called 8-deoxy-14,15-
dihydro-15-chloro-14-hydroxy-8,9-dehydro-Sclareol suggesting the epoxide formation as an reaction intermediate ${ }^{15}$.

In this study, the fungitoxic effect against $B$. cinerea of the natural diterpenoids Sclareol and 13-epi-Sclareol was characterized. Also, the effect of both diterpenoids on oxygen consumption and on plasmatic membrane integrity of $B$. cinerea was studied. Finally, biotransformation of Sclareol by $B$. cinerea was analysed.

\section{EXPERIMENTAL}

\subsection{General experimental procedures.}

The NMR spectra were acquired using a Bruker Avance $400 \mathrm{MHz}$ spectrometer $\left(400,133 \mathrm{MHz}\right.$ for ${ }^{1} \mathrm{H}, 100.624 \mathrm{MHz}$ for $\left.{ }^{13} \mathrm{C}\right)$. All the measurement were done in $\mathrm{CDCl}_{3}$ to $300 \mathrm{~K}$. Chemical shifts (in ppm) for ${ }^{1} \mathrm{H}$ and ${ }^{13} \mathrm{C}$ spectra, were calibrated to solvent signal, $\mathrm{CHCl}_{3} 7.26 \mathrm{ppm}$ (residual signal solvent) and $77.16 \mathrm{ppm}$, respectively, and reported relative to $\mathrm{Me}_{4} \mathrm{Si}$. Thin-layer chromatography was performed on Merck Kiesegel 60 F254, $0.2 \mathrm{~mm}$ thick and semi-preparative thin layer chromatography on Merck Kieselgel $60 \mathrm{~F}_{254}$ 20x 20cmx $0.25 \mathrm{~mm}$. Silica gel (Merck) was used for column chromatography. The melting point uncorrected was determined on a Kofler hot-stage apparatus. 2.2. Chemicals reagents and compounds used in this study.

Technical grade fungicide iprodione [3-(3,5-dichlorophenyl)- $N$-isopropyl2,4-dioxoimidazolidine-1-carboxamide] was provided from INIA (Santiago, Chile).

Diterpenoid structures used in this study are shown in Figure 1. Sclareol (Figure 1A) was obtained commercially, Sigma Chemical Co. (St. Louis, MO), whereas 13-epi-Sclareol (Figure 1B) was isolated and purified from resinous exudates of Pseudognaphalium cheiranthifolium as has been previously described with some modifications ${ }^{16}$. Briefly, the resinous exudates were obtained by dipping $P$. cheiranthifolium leaves and stems in $\mathrm{CH}_{2} \mathrm{Cl}_{2}$ during $30 \mathrm{~s}$ at room temperature. Extracts were concentrated by solvent evaporation in a rotary evaporator to a sticky residue. Residue was redissolved in $\mathrm{CH}_{2} \mathrm{Cl}_{2}$ and applied to a silica gel column $(30 \times 200 \mathrm{~mm})$. The column was eluted successively with hexane and hexane with increasing amount of ethyl acetate (9:1 to $1: 1$ hexane:ethyl acetate). 13-epi-Sclareol contained in the column fractions was further purified by thin layer chromatography using hexane:ethyl acetate $3: 1$. The last step of purification was by recrystallization using methanol as solvent. Finally, purified 13-epi-Sclareol was analyzed by comparison of their physical and spectroscopic ( ${ }^{1} \mathrm{H}$ NMR) data with literature ${ }^{16}$.

\subsection{Fungal isolate and culture conditions.}

During this study G29 isolate of B. cinerea was used. This strain was originally isolated from a naturally infected grape (Vitis vinifera) from Chile ${ }_{17}$ and was maintained on malt-yeast extract agar $(2 \%(\mathrm{w} / \mathrm{v})$ malt extract, $0.2 \%$ $(\mathrm{w} / \mathrm{v})$ yeast extract and $1.5 \%(\mathrm{w} / \mathrm{v})$ agar) at $4{ }^{\circ} \mathrm{C}$. The fungus was grown in the dark on malt-yeast extract agar medium $[2 \%(\mathrm{w} / \mathrm{v})$ malt extract, $0.2 \%$ $(\mathrm{w} / \mathrm{v})$ yeast extract and $1.5 \%(\mathrm{w} / \mathrm{v})$ agar) or soft agar $(2 \%(\mathrm{w} / \mathrm{v})$ malt extract, $0.2 \%(\mathrm{w} / \mathrm{v})$ yeast extract and $0.6 \%(\mathrm{w} / \mathrm{v})$ agar]. In studies related to action mechanism, liquid minimum medium was used. This medium was composed by $\mathrm{KH}_{2} \mathrm{PO}_{4}(1 \mathrm{~g} / \mathrm{L}), \mathrm{K}_{2} \mathrm{HPO}_{4}(0.5 \mathrm{~g} / \mathrm{L}), \mathrm{MgSO}_{4} \times 7 \mathrm{H}_{2} \mathrm{O}(0.5 \mathrm{~g} / \mathrm{L}), \mathrm{KCl}(0.5 \mathrm{~g} / \mathrm{L})$, 
$\mathrm{FeSO}_{4} \times 7 \mathrm{H}_{2} \mathrm{O}(0.01 \mathrm{~g} / \mathrm{L}) \mathrm{pH} 6.5,25(\mathrm{~mol} / \mathrm{L})$ ammonium tartrate as a nitrogen source, and supplemented with $1 \%(\mathrm{w} / \mathrm{v})$ glucose as carbon source.

2.4. Effect of the compounds on the mycelial growth of B. cinerea in solid media.

Fungitoxicity of both diterpenoids and the commercial fungicide iprodione was assessed using the radial growth test on malt-yeast extract agar ${ }^{11}$. Sclareol and 13-epi-Sclareol were dissolved in methanol at different final concentrations $(150,200$ and $250 \mu \mathrm{g} / \mathrm{mL})$. The diterpenoids were completely soluble at all concentration tested. One hundred $\mu \mathrm{L}$ of this solution were added to $20 \mathrm{~mL}$ of malt-yeast extract agar. The final methanol concentration was identical in controls and treatment assays. The medium with or without diterpenoids or iprodione was poured into $9 \mathrm{~cm}$ diameter Petri dishes. Dishes were left open in a biosecurity hood for $40 \mathrm{~min}$ to remove methanol. After evaporation of the solvent, the Petri dishes were inoculated with $0.5 \mathrm{~cm}$ agar discs with thin mycelium of $B$. cinerea. Cultures were incubated in the dark at $22{ }^{\circ} \mathrm{C}$ during several days. Mycelial growth diameters were measured daily. Results were also expressed as $\mathrm{IC}_{50}$ (the concentration that reduced mycelial growth by $50 \%$ ) determined by regressing the inhibition of radial growth values (percent control) against the values of compound concentration. Each experiment was done at least in triplicate.

\subsection{Effect of the compounds on germination of $\mathbf{B}$. cinerea conidia.}

Conidial germination assays were carried out on microscope slides coated with soft agar medium (2 $\mathrm{mm}$ thickness). Sclareol and 13-epi-Sclareol were added dissolved in methanol at a final concentration of $40 \mu \mathrm{g} / \mathrm{mL}$. Methanol was allowed to evaporate prior to inoculation. The slides were inoculated with dry conidia obtained from sporulated mycelia (1 week old), placed in a humid chamber $\left(90 \%\right.$ relative humidity), and incubated in the dark at $22{ }^{\circ} \mathrm{C}$ for $7 \mathrm{~h}$. Conidial germination was determined directly on the slides at intervals of 1 hour. The percentage of germination was estimated by counting the number of germinated conidia in five microscope fields each containing approximately 40 conidia. Conidia were judged to have germinated when the germ tube length was equal to or greater than conidial diameter. Each experiment was done at least in triplicate.

2.6. Mode of action of both labdane-type diterpenoids on $\mathrm{B}$. cinerea.

2.6.1. Determination of the effect of diterpenoids on the membrane integrity of B. cinerea. To analyze if Sclareol and 13-epi-Sclareol are able to produce alteration of the integrity of $B$. cinerea cytoplasmic membrane, SYTOX Green uptake assay according to described by Cotoras et al. $(2011)^{10}$ was used. $B$. cinerea conidia at a final concentration of $1 \times 10^{5}$ conidia / $\mathrm{mL}$ were inoculated in 24-well plates (lined with 12-mm glass coverslips) containing $1 \mathrm{~mL}$ of liquid minimum medium. Cultures were incubated at $22{ }^{\circ} \mathrm{C}$ for $15 \mathrm{~h}$ to permit the germination of the conidia. After this time, liquid medium was removed and same medium with $70 \%(\mathrm{v} / \mathrm{v})$ ethanol (positive control), $8 \%(\mathrm{v} / \mathrm{v})$ methanol (negative control), or $150 \mu \mathrm{g} / \mathrm{mL}$ of compounds was added to each well. The mixtures were incubated at $22^{\circ} \mathrm{C}$ for one or four hours in the case of diterpenoids and methanol or for 10 min when ethanol was used. $B$. cinerea hyphae adhered to glass coverslips were washed three times with liquid minimum medium and were stained with $50 \mathrm{nmol} / \mathrm{L}$ SYTOX Green. After $10 \mathrm{~min}$ of incubation, the hyphae were washed with minimum medium and glass coverslips containing hyphae were mounted in slides. For the assembly of the samples in the slides, $15 \mu \mathrm{L}$ of DABCO (1,4-diazabicyclo[2.2.2]octane) (Sigma Chemical Co., St. Louis, MO, USA) was used. The fluorescence of $B$. cinerea hyphae stained with SYTOX Green was observed under a confocal microscope (Carl Zeiss LSM 510) at an excitation wavelength of $488 \mathrm{~nm}$ and an emission wavelength of $540 \mathrm{~nm}$. These experiments were done at least in triplicate.

2.6.2. Determination of the effect of diterpenoids on the oxygen consumption of $\mathrm{B}$. cinerea conidia. Oxygen consumption was determined polarographically at $25{ }^{\circ} \mathrm{C}$ with a Hansatech oxygen electrode by using germinating conidia in a total volume of $1 \mathrm{~mL}$ according the protocol previously described ${ }^{10}$. To obtain conidia in suspension, Murashige and Skoog's basal medium at 4.4 $(\mathrm{g} / \mathrm{L})$ (Phytotechnology Laboratories, Lenexa, KS, USA) was added to Petri dishes containing conidia. The conidia were harvested by scraping with a sterile spatula. To eliminate mycelium, the suspension was filtered through glass wool. The conidia concentration was adjusted to $1 \times 10^{7}$ conidia/mL with minimum liquid media, in the presence of $2 \%(\mathrm{w} / \mathrm{v})$ glucose. Conidia were incubated for 2 hours at $22^{\circ} \mathrm{C}$. The measurement of basal oxygen consumption was carried out for $2 \mathrm{~min}$ in the same minimum liquid medium. After this time, $10 \mu \mathrm{g} / \mathrm{mL}$ carbonyl cyanide m-chloro-phenylhydrazone (CCCP), $650 \mu \mathrm{g} / \mathrm{mL}$ $\mathrm{KCN}$ or the diterpenoids, dissolved in methanol, at a final concentration of 150 and $250 \mu \mathrm{g} / \mathrm{mL}$ were added. Oxygen consumption was determined for eight more minutes.

Statistical Analyses. The effect of diterpenoids on mycelium growth and oxygen consumption by germinating conidia was evaluated using a one way analysis of variance (Genstat 5, Realease 4.1). Means were separated using the least significant difference test $(P \leq 0.05)$.

2.7. Biotransformation of Sclareol by B. cinerea.

The fungus was grown in liquid minimum medium for three days. Three days old mycelia were transferred to flasks with liquid minimum medium supplemented with $1 \%(\mathrm{w} / \mathrm{v})$ glucose in the presence of $150 \mu \mathrm{g} / \mathrm{mL}$ Sclareol. As control, cultures containing only Sclareol at $150 \mu \mathrm{g} / \mathrm{mL}$ in the absence of the fungus and cultures of the fungus in the absence of Sclareol were used. All cultures were incubated during one week at $22^{\circ} \mathrm{C}$ and stirred at $180 \mathrm{rpm}$. After this time, the mycelia were filtered and the fermentation broths were extracted three times with ethyl acetate, chloroform or hexane. The extracts were treated with sodium chloride to obtain a homogeneous solution and dried over anhydrous sodium sulphate, and the solvent was then evaporated. The extracts were analysed by thin layer chromatography (TLC) eluting with chloroform: ethyl acetate mixture $(95: 5, \mathrm{v} / \mathrm{v})$. The purification of the main compound obtained from Sclareol biotransformation was carried out by using semi-preparative thin layer chromatography with chloroform:ethyl acetate (95:5) as an eluent system.

Labda-14-en-3 $\beta, 8 \alpha, 13 \beta$ triol (compound 3, Figure 6) was obtained as a white solid, mp $162^{\circ} . \delta\left(\mathrm{CDCl}_{3}\right) 0.76(3 \mathrm{H}, \mathrm{s}, \mathrm{H}-19), 0.80(3 \mathrm{H}, \mathrm{s}, \mathrm{H}-20), 0.99$ $(3 \mathrm{H}, \mathrm{s}, \mathrm{H}-18), 1.16(3 \mathrm{H}, \mathrm{s}, \mathrm{H}-17), 1.28(3 \mathrm{H}, \mathrm{s}, \mathrm{H}-16), 3.23(1 \mathrm{H}, \mathrm{dd}, \mathrm{J}=4.2$ and $11.2 \mathrm{~Hz}, \mathrm{H}-3 \alpha), 5.04(1 \mathrm{H}, \mathrm{dd}, \mathrm{J}=1.3$ and $10.6 \mathrm{~Hz}, \mathrm{H}-15), 5.23(1 \mathrm{H}, \mathrm{dd}, \mathrm{J}=1.3$ and $17.4 \mathrm{~Hz}, \mathrm{H}-15), 5.94(1 \mathrm{H}, \mathrm{dd}, \mathrm{J}=10.8$ and $17.4 \mathrm{~Hz}, \mathrm{H}-14) .{ }^{13} \mathrm{C}$ NMR data (Table 1).

Table 1: ${ }^{13} \mathrm{C}$ NMR data determined of Sclareol (Compound 1) and its biotransformation product $3 \beta$-hydroxysclareol (Compound 3 ).

\begin{tabular}{|c|c|c|}
\hline Carbon atom & Compound 1 & Compound 3 \\
\hline & $\delta \mathbf{c}(\mathbf{p p m})$ & $\delta \mathbf{c}(\mathbf{p p m})$ \\
\hline 1 & 39.9 & 39.4 \\
\hline 2 & 18.6 & 27.4 \\
\hline 3 & 42.2 & 79.2 \\
\hline 4 & 33.4 & 39.2 \\
\hline 5 & 56.2 & 55.3 \\
\hline 6 & 20.7 & 20.5 \\
\hline 7 & 44.3 & 45.2 \\
\hline 8 & 74.9 & 74.9 \\
\hline 9 & 61.8 & 61.6 \\
\hline 10 & 39.4 & 38.2 \\
\hline 11 & 19.2 & 19.5 \\
\hline 12 & 45.1 & 45.2 \\
\hline 13 & 73.8 & 74.0 \\
\hline 14 & 146.2 & 147.5 \\
\hline 15 & 111.3 & 111.8 \\
\hline 16 & 27.4 & 28.5 \\
\hline 17 & 24.4 & 24.6 \\
\hline 18 & 33.5 & 30.0 \\
\hline 19 & 21.6 & 20.6 \\
\hline 20 & 15.5 & 15.9 \\
\hline
\end{tabular}

\section{RESULTS AND DISCUSSION}

\subsection{Antifungal activity of diterpenoids on B. cinerea.}

The antifungal activity of Sclareol (Compound 1) and 13-epi-Sclareol (Compound 2) (Figure 1), two labdane-type diterpenoids, against $B$. cinerea was analyzed. The difference among these compounds is the configuration in the C-13. The Sclareol has configuration S and 13-epi-Sclareol configuration $\mathrm{R}$. 
<smiles>C=C[C@H](O)C[C@H]1[C@@]2(C)CCCC(C)(C)C2CC[C@@]1(C)O</smiles>

1

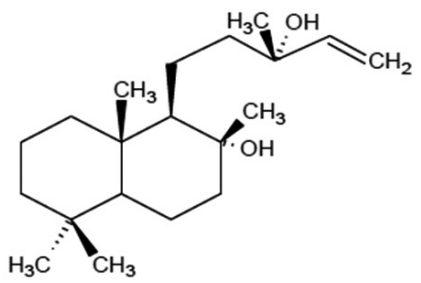

2
Figure 1. Structure of labdane-type diterpenoids, Sclareol (1) and 13-epiSclareol (2).

To determine the antifungal activity of the diterpenoids, the effect of Sclareol and 13-epi-Sclareol on mycelium growth in solid media was evaluated (Figure 2).
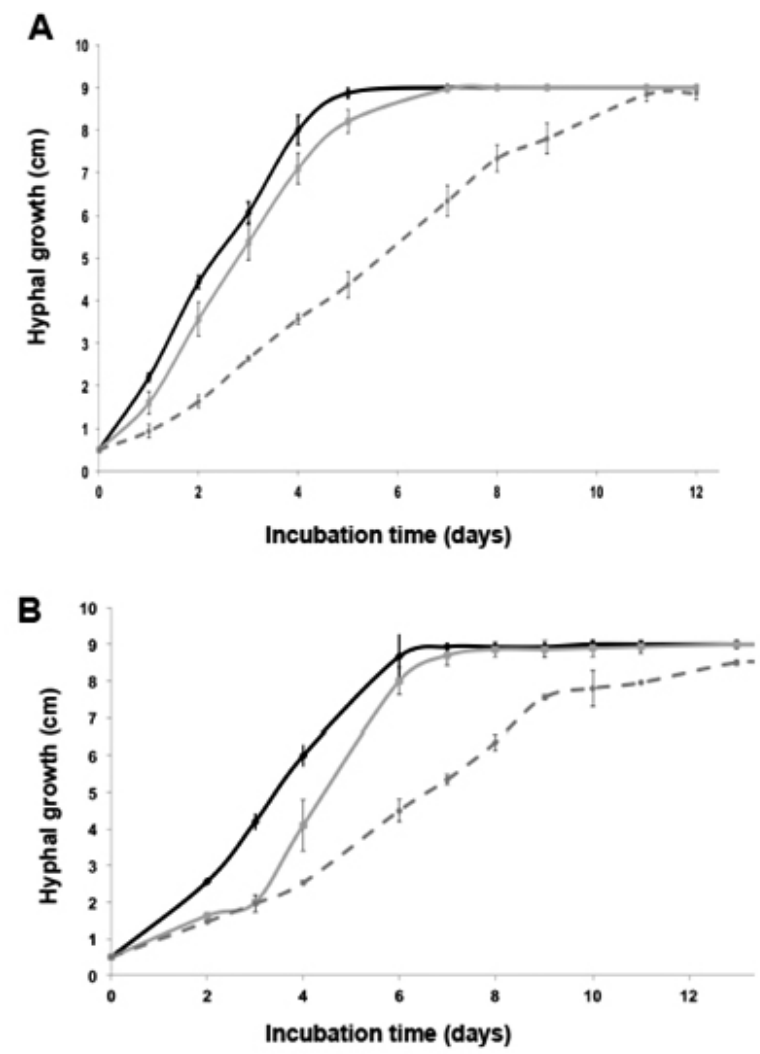

Figure 2. Effect of Sclareol and 13-epi-Sclareol on the mycelium growth of isolate G29 of B. cinerea. Sclareol (A) and 13-epi-Sclareol (B) were dissolved in methanol and were added at a final concentration of $150 \mu \mathrm{g} / \mathrm{mL}$ (dashed line). As a control: G29 in the absence (black line) or in presence of methanol (gray line) at the same concentration that treatments were used. Every point represents the average of three independent assays \pm standard deviation.

Both diterpenoids produced inhibition of the B. cinerea mycelium growth. In control, mycelium growth reached a maximum after seven days of incubation. Meanwhile, in the presence of Sclareol at $150 \mu \mathrm{g} / \mathrm{mL}$ maximum mycelium growth was reached after 11 days. On the other hand, in the presence of 13-epi-Sclareol at the same concentration $(150 \mu \mathrm{g} / \mathrm{mL})$ the maximum mycelium growth was reached after 12 days. Similar results were obtained when 200 or $250 \mu \mathrm{g} / \mathrm{mL}$ of Sclareol or 13-epi-Sclareol were used (data not shown). The diterpenoids decreased the rate of mycelium growth.

The inhibition percentages of myceliaum growth were calculated after four days of incubation and the concentration of the compounds that inhibited a $50 \%$
$\left(\mathrm{IC}_{50}\right)$ the mycelial growth was calculated (Table 2). Sclareol was slightly more active than 13-epi-Sclareol, since it presented a lower $\mathrm{IC}_{50}$ value. Although both diterpenoids were able to reduce the hyphal growth, the $\mathrm{IC}_{50}$ values were highest than those obtained for the commercial fungicide, Iprodione.

Table 2: Effect of Sclareol and 13-epi-Sclareol on in vitro mycelial growth of $B$. cinerea.

\begin{tabular}{|c|c|}
\hline Compounds & $\begin{array}{c}\mathbf{I C}{ }^{*}{ }^{*} \\
(\boldsymbol{\mu g} / \mathbf{m L} \mathbf{L})\end{array}$ \\
\hline Sclareol & $237.6 \pm 12.2 \mathrm{a}$ \\
\hline 13-epi-Sclareol & $268.8 \pm 9.8 \mathrm{~b}$ \\
\hline Iprodione & $35.0 \pm 16.8 \mathrm{c}$ \\
\hline
\end{tabular}

"Estimation of $\mathrm{IC}_{50}$ was based on colony diameter measurements after 4 days of incubation. Different letters represent significant differences $(\mathrm{P} \leq 0.05)$

Complementary to this, the effect of Sclareol and 13-epi-Sclareol on conidia germination was evaluated. The Figure 3 shows the kinetics of germination of $B$. cinerea conidia in the presence of both diterpenoids at 40 $\mu \mathrm{g} / \mathrm{mL}$.
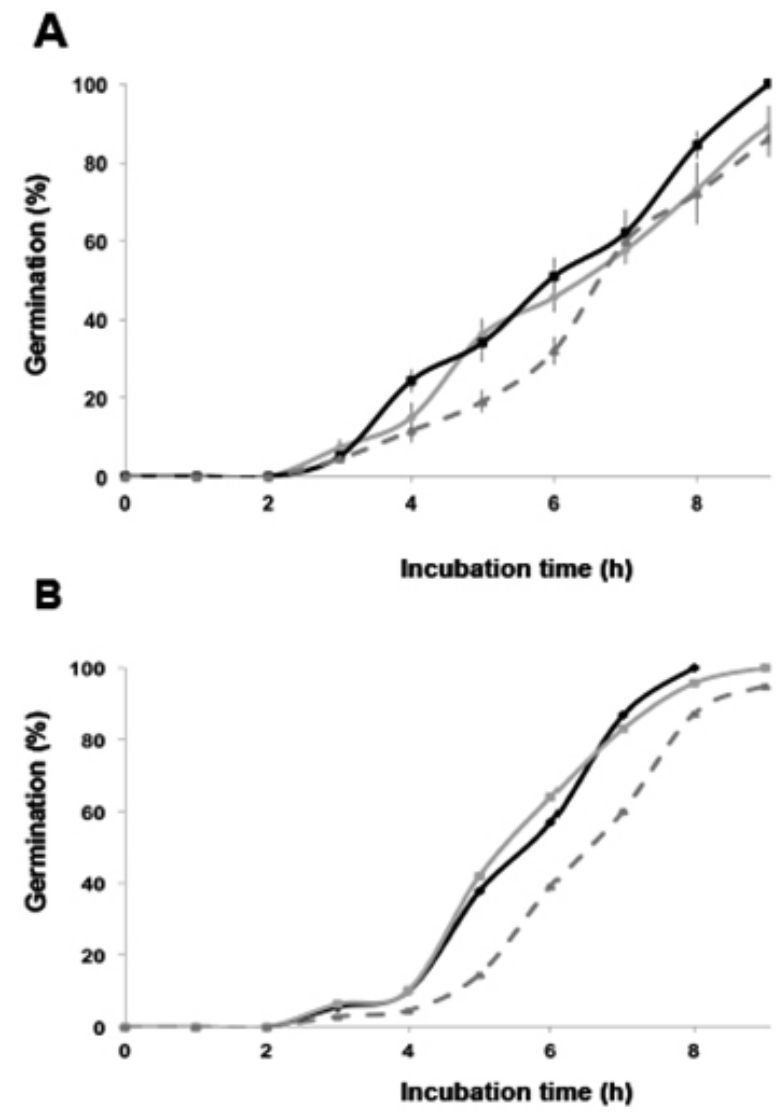

Figure 3. Effect of the diterpenoids on conidia germination of $B$. cinerea. Sclareol (A) and 13-epi-Sclareol (B) were dissolved in methanol and added at a final concentration of $40 \mu \mathrm{g} / \mathrm{mL}$ (dashed line). G29 incubated in the absence (black line) or in the presence of methanol at the same concentration that treatments were used (grey line) as control. The germination kinetic was followed during 10 hours of incubation at $22{ }^{\circ} \mathrm{C}$. Each point represents the average of three independent assays \pm standard deviation.

The diterpenoids were not able to inhibit the germination. However, 13-epi-Sclareol produced a delay in germination between the 4 and 7 hours of incubation, but later, a $100 \%$ of germination was obtained (Figure 3B). In presence of the diterpenoids, the appearance of cytological abnormalities 
was not observed (data not shown). This result was different to those obtained with resveratrol, a natural phytoalexin; since it has been reported that this compound produced curved germ tubes and cytological abnormalities in $B$. cinerea conidia $^{18}$.

It is important to emphasize that this is the first work in which the antifungal effect against the fungus $B$. cinerea of two epimers was compared.

\subsection{Mode of action of Sclareol and 13-epi-Sclareol on B. cinerea.}

To analyze the possible mechanism of action of Sclareol and 13-epiSclareol on $B$. cinerea, the effect of these diterpenoids on the plasmatic membrane integrity or conidia oxygen consumption was determined.

To determine if the diterpenoids cause damage in the integrity of the fungal plasmatic membrane, the assay of SYTOX green uptake was performed. This assay is based in the uptake of the dye SYTOX green, that fluoresces upon interaction with nucleic acids and it is able to penetrate cells with compromised plasmatic membrane; but it does not cross the membranes of non-compromised living cells ${ }^{19}$. The results of these experiments are shown in the Figure 4.
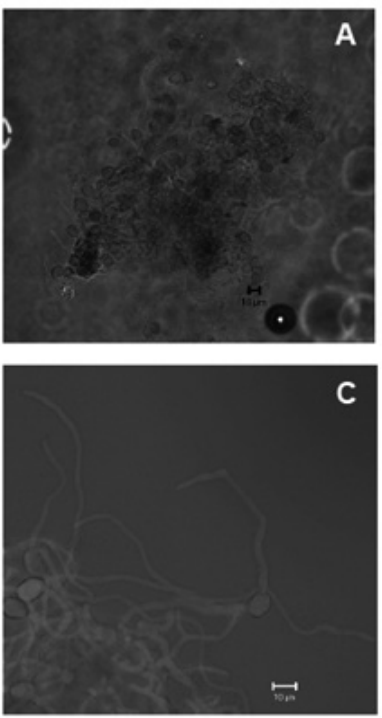
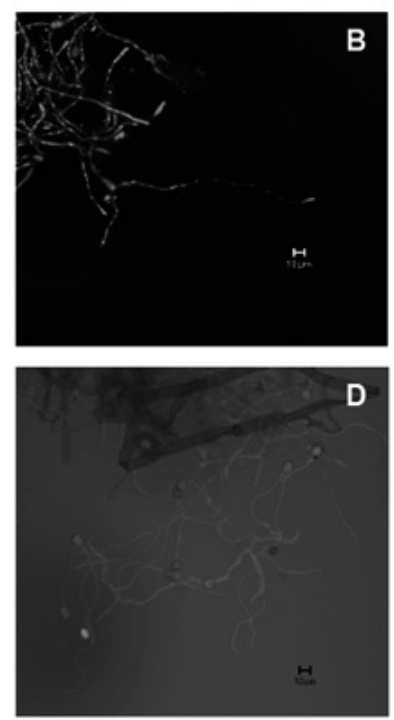

Figure 4: Effects of Sclareol and 13-epi-Sclareol on plasmatic membrane integrity of $B$. cinerea Conidia, at a final concentration of $1 \times 10^{5}$ conidia/ $\mathrm{mL}$, were incubated in liquid minimum medium in the presence of $10 \%(\mathrm{v} / \mathrm{v})$ methanol (A), 70\% (v/v) ethanol (B), $150 \mu \mathrm{g} / \mathrm{mL}$ of Sclareol during $4 \mathrm{~h}(\mathbf{C})$ or $150 \mu \mathrm{g} / \mathrm{mL}$ of 13-epi-Sclareol during $4 \mathrm{~h}$ (D) The fluorescence of $B$. cinerea hyphae stained with SYTOX Green was observed under a confocal microscope. These photographs are representatives of three independent experiments

It is possible to observe that no fluorescence was detected in presence of methanol (negative control, Figure 4A), by the contrary, in presence of ethanol, a positive control, fluorescent nuclei were observed (Figure 4B). The fluorescence detected in presence of ethanol is due this compound generates dehydration of the cellular membrane producing damage in the membrane integrity of the fungus. In presence of Sclareol or 13-epi-Sclareol, fluorescence in the nuclei was not observed (Figure 4C y 4D). Therefore, it is possible to conclude that these diterpenoids did not alter plasmatic membrane integrity.

On the other hand, to analyse the effect of the diterpenoids on mitochondrial respiratory chain, the oxygen consumption by germinating conidia was determined. Both diterpenoids, at a concentration of $150 \mu \mathrm{g} / \mathrm{mL}$, increased the oxygen consumption of germinating conidia respecting to the basal consumption, therefore these compounds would act as uncoupler of the oxidative phosphorylation. Indeed, the percentages of oxygen consumption in the presence of Sclareol or 13-epi-Sclareol were $156.7 \%$ or $162.2 \%$, respectively. Similar results were obtained at a concentration of $250 \mu \mathrm{g} / \mathrm{mL}$ of both diterpenoids where the oxygen consumption in the presence of Sclareol or 13-epi-Sclareol increased to $155.7 \%$ or $140.8 \%$, respectively (Figure 5).

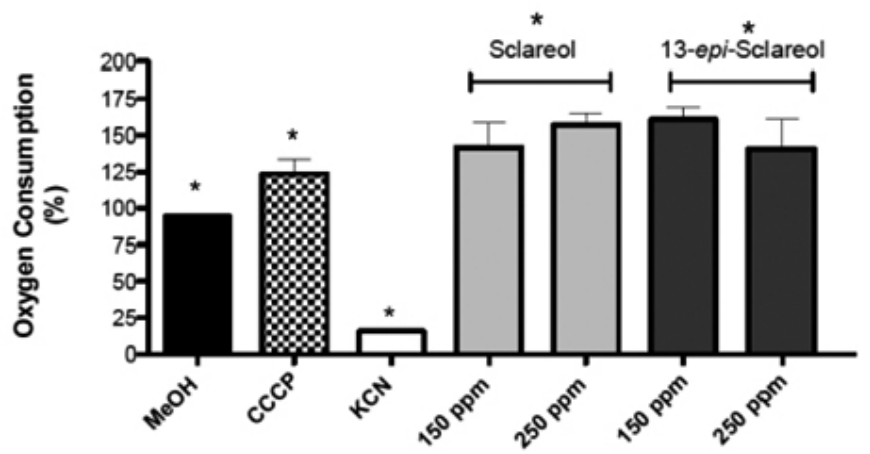

Figure 5: Effect of the diterpenoids on oxygen consumption of $B$. cinerea germinating conidia. Diterpenoids were aggregated at a final concentration of 150 or $250 \mu \mathrm{g} / \mathrm{mL}$ to a conidia suspension $\left(1 \times 10^{7}\right.$ conidia $\left./ \mathrm{mL}\right)$ in minimal media with $2 \% \mathrm{w} / \mathrm{v}$ glucose; the oxygen consumption were measured at room temperature using a Clark electrode. Each bar represents the average of at least three independent experiments \pm standard deviation. The symbol (*) represents significant differences $P \leq 0.05$

In presence of CCCP, an uncoupler of oxidative phosphorylation, also an increase of the oxygen consumption was observed, reaching to $124 \%$. Instead, in presence of $\mathrm{KCN}$, a respiratory chain inhibitor, the oxygen consumption diminished to $15.9 \%$.

These results suggest that the diterpenoids are able to cross the plasmatic membrane without alter it, then they reach to the mitochondria causing uncoupling of the oxidative phosphorylation. An overlapping study between Sclareol and cholesterol based on their corresponding polar and hydrophobic molecular segments, calculated from their lypophilic profiles, revealed their space similarities, both molecules are amphipathic and they possess lipophilic and hydrophilic segments that can be easily superimposed. It was shown that Sclareol was incorporated in phospholipid membrane model imitated the thermal effect from the cholesterol ${ }^{20}$. Based on the structural similarity among cholesterol and ergosterol, a fungal membrane steroid, it could be suggested that Sclareol or 13-epi-Sclareol would interact with the fungal mitochondrial membrane, being able to dissipate the protonic gradient indirectly, acting as uncoupler of the oxidative phosphorylation.

Different results were obtained in Gram positive bacteria treated with 13-epi-Sclareol ${ }^{21}$ Tapia et al. (2004) reported that this compound inhibited oxygen consumption in intact Gram-positive. In addition, the authors described that the diterpenoid was able to inhibit NADH oxidase and cytochrome $\mathrm{C}$ reductases activities suggesting that the target site of 13-epi-Sclareol was located between coenzyme $\mathrm{Q}$ and cytochrome $\mathrm{C}$ of the bacterial respiratory chain $^{21}$.

\subsection{Biotransformation of Sclareol by B. cinerea.}

In this work, the biotransformation of Sclareol was analyzed. For this, $B$. cinerea mycelium was incubated with Sclareol, at $150 \mu \mathrm{g} / \mathrm{mL}$, in a culture medium supplemented with $1 \%$ glucose. After seven days of incubation, compounds were extracted from culture medium by liquid-liquid extraction using solvents with different polarity.

Thin layer chromatography analysis of the extracts revealed the presence of two main metabolites with higher polarities than Sclareol, but only one biotransformed compound was isolated. This compound was purified and analyzed through ${ }^{1} \mathrm{H}$ and ${ }^{13} \mathrm{C}$, and HSQC, NMR spectroscopy, ${ }^{1} \mathrm{H}$ NMR spectrum of the compound exhibited signals for H-3 $\left(\delta 3.23\right.$, dd $J_{3-2 \mathrm{a}}=11.2 \mathrm{~Hz}$, $J_{3-2 \mathrm{~b}}=4.2 \mathrm{~Hz}$ ). The ${ }^{13} \mathrm{C} \mathrm{NMR}$ showed a resonance at $\delta 79.2$ and a methylene resonance at $\delta 27.4$. The signal corresponded to C-3 appears now displaced to lower fields suggesting that the original position at $\delta 42.2$ and after at $\delta 79.2$ was displaced by the presence of an $(-\mathrm{OH})$ group in this carbon atom. The $2 \mathrm{D}$ spectrum, HSQC, displayed an important correlation between H-3 ( $\delta 3.23)$ / $\mathrm{C}-3(\delta 79.2)$. The ${ }^{1} \mathrm{H}$ assignments of biotransformed compound were compared with the values of labda-14-en-3 $\beta, 8 \alpha, 13-\beta$-triol obtained by fermentation of Sclareol with Cephalosporium aphidicola ${ }^{22}$ and it was concluded that Sclareol was transformed to labda-14-en-3 $\beta, 8 \alpha, 13 \beta$ triol, commonly called 3ß-hydroxysclareol (Figure 6). 


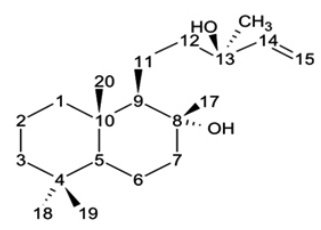

1

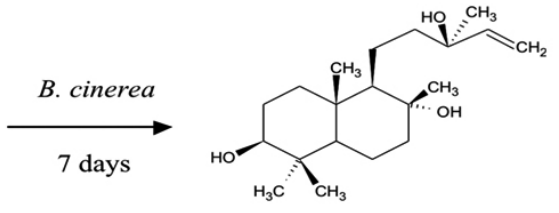

3
Figure 6: Product obtained by Sclareol biotransformation by B. cinerea.

It has been reported that Sclareol is biotransformed to more oxidized molecules by fungi and bacteria. Supporting this observation, Farooq and Tahara $(2007)^{15}$ reported the biotransformation of two cytotoxic terpenes ( $\alpha$-santonin and Sclareol) by $B$. cinerea. Sclareol was metabolized to epoxysclareol and to 8-deoxy-14,15-dihydro-15-chloro-14-hydroxy8,9 -dehydrosclareol, a rare example of halogenation ${ }^{15}$. In addition, it has

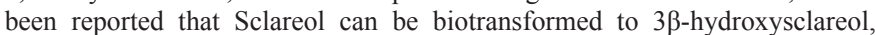
$6 \alpha$-hydroxysclareol or 18-hydroxysclareol by Aspergillus alliaceus, A. spergillus niger, A. spergillus ochraceus, Cunninghamella echinulata, Cunninghamella elegans, Cunninghamella species, C. urvularia lunata, M. ortierella ramanniana, M. ortierella isabellina, Rhizopus arrhizus, $R$. hizopus stolonifer, and Sporotrichum exile ${ }^{14}$. In addition, several oxidized metabolites were obtained in the biotransformation of Sclareol by the fungus Cephalosporium aphidicola. Among the main products, the compounds labda-14-en- $8 \alpha, 13-\beta, 18$-triol, labda-14-en- $3 \beta, 8 \alpha, 13 \beta$ triol were produced ${ }^{22}$. In the case of hydroxylation of Sclareol by Bacillus sphaericus the $3 \beta$-hydroxysclareol was obtained with a $40 \%$ yield and 18 -hydroxysclareol (10\% yield). It has been informed that the hydroxylation in the C-3 position of the Sclareol it is the most frequently reaction ${ }^{23}$. However, this is the first study that reports that $3 \beta$-hydroxysclareol was produced as biotransformation product from Sclareol by $B$. cinerea.

Finally, the results from this work contribute to the evaluation of natural products Sclareol as potential preventive treatments against $B$. cinerea.

\section{CONCLUSIONS}

It was possible to conclude that the diterpenoids, Sclareol and 13-epiSclareol were able to reduce the mycelial growth of $B$. cinerea. The inhibitory effect would be related to uncoupling of fungal oxidative phosphorylation. In addition, Sclareol was biotransformed by Botrytis to $3 \beta$-hydroxysclareol.

\section{ACKNOWLEDGMENTS}

This research was supported of the Universidad de Santiago de Chile, FONDECYT (1130389) and FONDEF (CA12i10054) Grants.

\section{REFERENCES}

1. W.R. Jarvis Epidemiology. In The Biology of Botrytis; Coley-Smith, J. R., Verhoeff, K., Jarvis, W. R., Eds.; Academic Press: London, 1980, pp 219-250.

2. C.S. Thomas, J.J. Marois, J.T. English. Phytopathology 86, 260, (1988)

3. M. Esterio, C. Ramos, A.S. Walker, S. Fillinger, P. Leroux, J. Auger, Phytopathol. Med. 50(3), 14, (2011)

4. P. Leroux, M. Gredt, M. Leroch, A.S. Walker. App. Env. Microbiol. 76, 6615, (2010)

5. B.A. Latorre, R. Torres. Crop Protect. 40, 49, (2012)

6. M. Esterio, J. Auger, C. Ramos, H. García. Plant Dis. 91(6), 468, (2007)

7. E. Ghisalberti. Fitoterapia. 68, 303, (1997)

8. M. Tada, K. Okuno, K. Chiba, E. Ohnishi, T. Yoshii. Phytochemistry 35, $539,(1994)$

9. A. Rahman, A. Nasreen, F. Akhtar, M. Shekhani, J. Clardy, M. Parvez. J. Nat. Prod. 60, 472, (1997)

10. M. Cotoras, L. Mendoza, A. Muñoz, P. Yáñez, P. Castro, M. Aguirre. Molecules 16, 3885, (2011)

11. M. Cotoras, C. Folch, L. Mendoza. J. Agric. Food Chem. 52 ,2821, (2004)

12. L. Mendoza, P. Espinoza, A. Urzúa, M. Vivanco, M. Cotoras. Molecules. 14, 1966, (2009)

13. J. Aleu, I.G. Collado. J. Mol. Cat. B: Enzymatic. 13 (4-6), 77 (2001)

14. L.M.T. Frija, R.F.M. Frade, C.A.M. Afonso. Chem. Rev., 111 (8), 4418 (2011)
15. A. Farooq, A.S. Tahara. Z. Naturforsch. 55c, 713 (2000)

16. A. Urzúa, R. Torres, C. Bueno, L. Mendoza, Biochem. Syst. Ecol. 23(4), 459, (1995)

17. G. Muñoz, P. Hinrichsen, Y. Brygoo, T. Giraud. Mycol. Res. 106, 594, (2002)

18. M. Adrian, H. Raaei, P. Jeandet, J. Veneau, L. Weston, R. Bessis, Phytopatology, 88, 472, (1998)

19. K. Thevissen, R. Franky, W. Broekaert. Appl. Env. Microbiol. 65, 5451, (1999)

20. I. Kyrikou, A. Georgopoulos, S. Hatziantoniou, T. Mavromoustakos, C. Demetzos. Chem. Phys. Lipids. 133, 125, (2005)

21. L. Tapia, J. Torres, L. Mendoza, A. Urzúa, J. Ferreira, M. Pavani, M. Wilkens. Planta Med. 70(11), 1058, (2004)

22. J. Hanson, P.B. Hitchcock, H. Nasir, A. Truneh. Phytochem. 36, 903, (1994)

23. A. Wolf-Rainer. Phytochem. 36, 1421, (1994) 